3.9 (2.7) and $17 \%$ presented peripheral arthritis during the first visit. After a mean of 3.7 (2.4) years of follow-up, ASDAS and peripheral arthritis independently contributed to explaining BASFI changes over time. Contextual factors did not modify either of the relationships. A true longitudinal relation was proved with the autoregressive GEE model, showing that, adjusted for age, gender, spinal mobility and use of NSAIDs, an increase of one ASDAS unit led to a BASFI 0.48 units higher ( $\mathrm{B} 0.48[95 \% \mathrm{Cl} 0.39$ $0.57]$ ), and the presence of peripheral arthritis, to a BASFI 0.44 units higher ( $B 0.44$ [0.08-0.8]) (Table 1). A gradient was found for ASDAS disease activity states: ASDAS low disease activity (vs ASDAS inactive disease) with an increase in BASFI of 0.67 (0.35-0.98) units compared to ASDAS very high disease activity (vs ASDAS inactive disease) with a BASFI increase of 2.30 (1.90-2.72) units. (Figure 1) No interaction was found between peripheral arthritis and disease activity on BASFI, and similarly, no interactions were found between either ASDAS or peripheral arthritis with age, gender, educational level, smoking status, job type or comorbidities on BASFI.

Table 1. Factors longitudinally associated with BASFI

\begin{tabular}{lll}
\hline Assessment & $\begin{array}{l}\text { Model with ASDAS } \\
\text { continuous }\end{array}$ & $\begin{array}{l}\text { Model with ASDAS } \\
\text { categorical }\end{array}$ \\
& $\mathbf{B}(\mathbf{9 5 \%} \mathrm{Cl})$ & $\mathbf{B}(\mathbf{9 5 \%} \mathbf{C l})$ \\
& $\mathbf{n}=\mathbf{1 7 9}$ & $\mathbf{n}=\mathbf{1 7 9}$ \\
\hline Previous BASFI (0-10) & $0.47(0.41$ to 0.52$) \dagger$ & $0.44(0.39$ to 0.50$) \dagger$ \\
Age (years) & $0.007(-0.005$ to 0.02$)$ & $0.008(-0.004$ to 0.02$)$ \\
Male gender (vs female gender) & $-0.42(-0.79$ to -0.06$) \dagger$ & $-0.38(-0.74$ to -0.02$) \dagger$ \\
Peripheral arthritis & $0.44(0.08$ to 0.80$) \dagger$ & $0.38(0.03$ to 0.74$) \dagger$ \\
ASDAS-CRP & $0.48(0.39$ to 0.57$) \dagger$ & - \\
ASDAS-CRP categorical & & \\
Moderate vs inactive disease & - & $0.67(0.35$ to 0.98$) \dagger$ \\
High vs inactive disease & - & $1.70(1.37$ to 2.02$) \dagger$ \\
Very high vs inactive disease & - & $2.30(1.90$ to 2.72$) \dagger$ \\
BASMI (0-10) & $0.32(0.24$ to 0.41$) \dagger$ & $0.32(0.23$ to 0.40$) \dagger$ \\
NSAIDs $(\%)$ & $0.38(0.09$ to 0.66$) \dagger$ & $0.37(0.09$ to 0.64$) \dagger$
\end{tabular}

† Significant at $\mathrm{p}<0.05$.

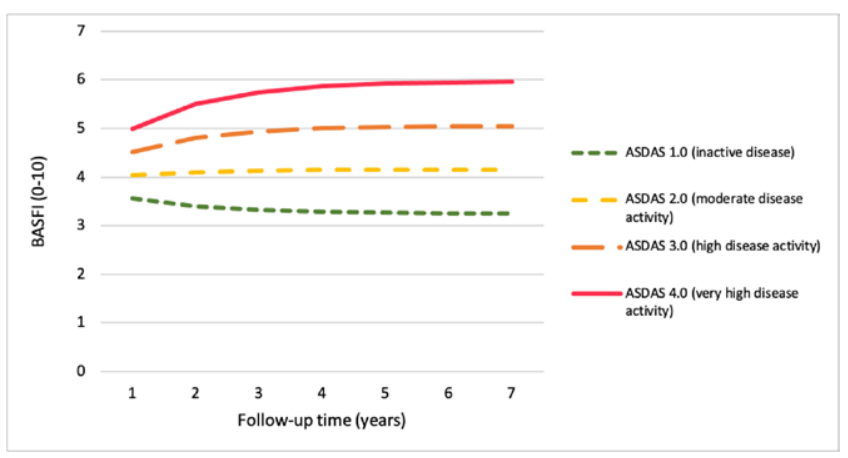

Figure 1. Longitudinal relationship between ASDAS and BASFI

Conclusion: Peripheral arthritis and higher disease activity independently lead to more functional impairment in axSpA. Contextual factors do not modify these relationships. Disclosure of Interests: Dafne Capelusnik Speakers bureau: BMS, Grant/ research support from: Pfizer, Sofia Ramiro Speakers bureau: Lilly, MSD, Novartis, UCB, Consultant of: AbbVie, Lilly, MSD, Novartis, UCB, Sanofi, Grant/ research support from: MSD, Emilce Edith Schneeberger Speakers bureau: Abbvie, BMS, Janssen, Eli Lilly, Boehringer Ingelheim, Pfizer, Grant/research support from: Pfizer, Gustavo Citera Speakers bureau: Abbvie, BMS, Janssen, Pfizer, Grant/research support from: Pfizer, BMS, Janssen

DOI: 10.1136/annrheumdis-2021-eular.743

\section{POS0954 \\ QUALITY OF LIFE IN CHRONIC BACK PAIN PATIENTS, A 2-YEAR COMPARISON BETWEEN PATIENTS WITH AND WITHOUT A DIAGNOSIS OF AXIAL SPONDYLOARTHRITIS: DATA FROM THE SPONDYLOARTHRITIS CAUGHT EARLY COHORT}

A. Boel ${ }^{1}$, M. Van Lunteren ${ }^{1}$, K. M. Fagerli ${ }^{2}$, S. Exarchou ${ }^{3}$, R. Ramonda ${ }^{4}$, M. Van de Sande ${ }^{5}$, D. Van der Heijde ${ }^{1}$, F. A. Van Gaalen ${ }^{1} .{ }^{1}$ Leiden University
Medical Centre, Rheumatology, Leiden, Netherlands; ${ }^{2}$ Diakonhjemmet Hospital, Rheumatology, Oslo, Norway; ${ }^{3}$ Lund University, Clinical Sciences, Section of Rheumatology, Malmö, Sweden; ${ }^{4}$ University of Padova, Medicine, Rheumatology Unit, Padova, Italy; ${ }^{5}$ Amsterdam University Medical Center, Rheumatology and Clinical Immunology, Amsterdam, Netherlands

Objectives: To study quality of life (QoL) in patients with a diagnosis of axial spondyloarthritis (axSpA) and how this relates to the QoL of patients without axSpA, after two-years of protocolised follow-up.

Methods: QoL was assessed using the Medical Outcomes Study 36-Item ShortForm Health Survey (SF-36). Age, sex and country weighted scale scores were calculated for each of the 8 subscales. Numeric scales ranged from 0 (worst health) to 100 (best health), after recoding and recalibration. The physical (PCS) and mental component summary (MCS) scores were calculated from the adjusted scores; and transformed to enable comparison to the general population mean of 50 .

Additionally, the proportion of patients with an improvement or worsening of the PCS and MCS above the minimal clinically important difference (MCID) were assessed. We applied the commonly used MCID in clinical trials with bDMARDs in axSpA of 3 points for the PCS and MCS.

In this study we included patients from the SPACE cohort (patients aged $>16$ years with chronic back pain suspected of axSpA) with a diagnosis axSpA or no axSpA all with a level of confidence $\geq 7$ (on a 0-10 scale) after locally read imaging. The PCS and MCS had to be available at baseline and 2-year follow-up too.

Linear regression models were used to test the difference between patients with and without axSpA at two-year follow-up for PCS and MCS scores. Baseline PCS and MCS scores and NSAID-use over time were tested as confounders. Results: Patients with a diagnosis of axSpA were more frequently male $(57 \%$ vs $27 \%$ ) and HLA-B27 positive (75\% vs $31 \%$ ) and had more SpA features at baseline [mean (SD) 5(2) vs 3(1)] compared to the patients without axSpA. Age, symptom duration and NSAID-use were similar between groups.

In both groups the PCS significantly improved over two years. The PCS was significantly better in the group with an axSpA diagnosis compared to the no axSpA group at two-year follow-up, after correction for baseline PCS scores and NSAID-use over time (table 1). Despite the improvements over time, PCS scores were still well below the general population mean of 50 in both groups at two-year follow-up. MCS scores were not significantly different between groups at follow-up, and they were close to the general population mean.

In linear regression models with baseline values and NSAID-use over time as covariates, axSpA was an independent predictor of better PCS scores.

Table 1. PCS and MCS scores at baseline and 2-year follow-up for the group with an axSpA diagnosis and those without axSpA (no axSpA)

\begin{tabular}{|c|c|c|c|c|c|}
\hline & $\begin{array}{l}\text { Diagnosis } \\
(\mathrm{N}=186) \\
\text { Baseline } 2\end{array}$ & 2 axSpA & $\begin{array}{l}\text { no axSpA } \\
(\mathrm{N}=74) \\
\text { Baseline }\end{array}$ & 2 years & $\begin{array}{l}\text { p-values between } \\
\text { groups at } 2 y r s\end{array}$ \\
\hline SF-36 PCS, mean (SD) \% & $28.0(14.8)$ & $\begin{array}{l}40.5 \\
(12.3)^{\dagger}\end{array}$ & $26.4(13.6)$ & $34.7(15.6)^{\dagger}$ & ${ }^{\dagger} p<0.001^{*}$ \\
\hline Improvement $>\mathrm{MCID}, \mathrm{n}(\%)$ & & $143(78)$ & & $49(66)$ & \\
\hline Worsening >MCID, $n(\%)$ & & $22(12)$ & & $12(16)$ & \\
\hline SF-36 MCS, mean (SD) \% & $47.3(13.7)$ & $47.9(11.8)$ & $46.5(11.2)$ & $48.9(10.6)$ & $p=0.364$ \\
\hline Improvement >MCID, $\mathrm{n}(\%)$ & & $76(42)$ & & $35(47)$ & \\
\hline Worsening $>$ MCID, $n(\%)$ & & $69(38)$ & & $26(35)$ & \\
\hline
\end{tabular}

*Significant difference between groups at two years; after correction for baseline PCS scores and NSAID use over time†Significant improvement within group over timeaxSpA, axial Spondyloarthritis; MCID, Minimal Clinically Important Difference; MCS, Mental Component Summary; PCS, Physical Component Summary; SF-36, Medical Outcomes Study 36-Item Short-Form Health SurveyPCS scores of the majority of patients in both groups improved more than the MCID over two-years of protocolised follow-up. The proportions of patients who improved or worsened more than the MCID in MCS scores were similar.

Conclusion: After two years of protocolised follow-up physical functioning was better in patients with an axSpA diagnosis compared to patients without axSpA but remained significantly compromised in both groups in comparison to the general population

Disclosure of Interests: None declared

DOI: 10.1136/annrheumdis-2021-eular.769 